\title{
Avaliação e qualidade no Ensino Superior: os impactos do período 1995-2002
}

\author{
Giselle Cristina Martins Real \\ Universidade Federal da Grande Dourados
}

\section{Resumo}

0 objetivo deste trabalho consiste em apreender os impactos que a política de avaliação da Educação Superior adotada no período de 1995 a 2002 proporcionou à construção da concepção de qualidade nas instituições de Ensino Superior de forma a compreender a sua lógica intrínseca. Adotou-se como procedimento metodológico a análise documental, a partir dos resultados da sistemática de avaliação desenvolvida pelo Ministério da Educação - MEC - para os cursos de graduação, no período em tela, que considerou os seguintes instrumentos de avaliação: o Exame Nacional de Cursos; as avaliações desenvolvidas por pares para fins de autorização e reconhecimento de cursos; e as informações estatísticas. Para a análise dos relatórios das comissões de avaliação, procedeu-se a um recorte geográfico, considerando as avaliações processadas no estado de Mato Grosso do Sul. Como resultados, observou-se que a avaliação, a partir de 1995, passa a ser utilizada como um mecanismo de expansão de cursos e instituições, a partir da configuração de concepções distintas de qualidade, estabelecidas de acordo com a organização administrativa das instituições de Ensino Superior, o que conformou a diversificação existente constituída por universidade, centro universitário e faculdade. Apesar do impacto positivo da avaliação, observado no contexto institucional, as evidências encontradas permitem apontar para um esgotamento do poder indutor da avaliação na melhoria da qualidade do ensino, na medida em que as instituições vêm procurando atender aos padrões de qualidade estabelecidos pelo MEC em seus aspectos formais sem, contudo, alterar a essência da qualidade do ensino que oferecem.

\section{Palavras-chave}

Avaliação educacional - Educação Superior - Política educacional - Qualidade na educação.

Correspondência: 


\title{
Evaluation and quality in Higher Education: the impacts of the 1995-2002 period
}

\author{
Giselle Cristina Martins Real \\ Universidade Federal da Grande Dourados
}

\begin{abstract}
The objective of this work consists in apprehending the impacts that the evaluation policy for Higher Education adopted during the 19952002 period had for the construction of the concept of quality in institutions of Higher Education, so as to understand its intrinsic logic. The methodological procedure adopted relied on the documental analysis of the results obtained with the evaluation system developed by the Ministry for Education - MEC - for undergraduate courses during the period under consideration here, which incorporated the following evaluation instruments: the National Courses Exam (Exame Nacional de Cursos); the peer evaluations carried out for the purpose of course accreditation; and statistical data. The analysis of the reports from evaluation committees followed the geographical criterion of selecting only evaluations conducted for the State of Mato Grosso do Sul. Results showed that since 1995 the evaluation process has been used as a mechanism for the expansion of courses and institutions, based on the establishment of different concepts of quality suited to the administrative organization of the institutions of Higher Education, crystallizing the existing variety constituted by universities, university centers, and colleges. Despite the positive impact of evaluation observed in the institutional sphere, the evidence gathered here points to the exhaustion of the power of evaluation to promote further improvements in the quality of education, since institutions have been seeking to comply with the formal aspects of the quality standards set up by MEC without actually changing the essential quality of the education they offer.
\end{abstract}

\section{Keywords}

Evaluation of education - Higher Education - Education policy Quality of education. 
0 presente trabalho procura agregar ao debate acerca da avaliação do Ensino Superior um novo componente, que tem como pressuposto acatar a lógica interna da sistemática de avaliação e, a partir dela, cotejar os resultados internos processados pelo conjunto dos instrumentos utilizados, com a finalidade de apreender os impactos que essa sistemática engendrou no contexto das instituições do Ensino Superior. Com isso, mesmo conhecendo a crítica da validade do Exame Nacional de Cursos - ENC ou provão (Santos, 2001; Rothen, 2003; Dias Sobrinho, 2003) como um instrumento de melhoria da qualidade do ensino, incorpora-se seus resultados como fonte da pesquisa, como uma forma de compreender os nexos entre os instrumentos que compõem a sistemática de avaliação adotada no período de 1995 a 2002.

Estudos acadêmicos desenvolvidos no período em tela processaram a crítica à política nacional de Educação Superior, sobretudo àquela indutora do processo de avaliação (Cunha, 2003; 2004; Gomes, 2003; Ristoff, 2003; Dias Sobrinho, 2003; Dourado; Oliveira; Catani, 2003). Esses estudos evidenciaram a constituição de um estado avaliador no contexto brasileiro que, a partir da adoção de um "ethos competitivo" (Afonso, 2000; Neave, 1988; 1998), classificava as instituições por meio da avaliação do rendimento do aluno, gerando competição, ao mesmo tempo em que pretendia induzir a melhoria na qualidade do ensino. Esses estudos, ao processarem a crítica e revelar a lógica implícita à sistemática de avaliação adotada, buscavam contribuir para a política educacional, apontando os vícios e uma qualidade questionável gerada pela política adotada (Santos, 2001) diante dos valores anunciados constituintes da República Federativa Brasileira.

Para o desenvolvimento da pesquisa que deu origem ao presente artigo, adotou-se como procedimento metodológico a análise documental, considerando os seguintes instrumentos de avaliação utilizados no período de 1995 a 2002: o ENC; os relatórios das comissões de avaliações desenvolvidas por pares para fins de autorização e reconhecimento de cursos ${ }^{1}$; e as informações estatísticas. No que se refere aos relatórios das comissões de avaliações, devido à grande dimensão quantitativa dos documentos, foi realizado um recorte geográfico, optando-se por considerar os relatórios das avaliações realizadas no estado de Mato Grosso do Sul.

Divide-se o presente trabalho em três partes, sendo que a primeira analisa o processo de avaliação da qualidade implementado na Educação Superior. A segunda aponta para os impactos que a sistemática de avaliação produziu nas instituições de Ensino Superior e, por fim, apresentam-se algumas considerações finais que explicitam a perda do poder indutor da avaliação em proporcionar o salto de qualidade na Educação Superior brasileira pretendida, de acordo com os moldes em que vem sendo implementada.

\section{- processo de avaliação da qualidade da Educação Superior brasileira}

Embora o conceito de qualidade seja complexo (Dias Sobrinho, 2003; Diker, 1996; Rios, 2002), a sua apreensão é possível quando se busca identificar as concepções presentes na política educacional formulada e suas formas de implementação. Nesse sentido, o conceito de qualidade adotado neste trabalho se fundamenta na concepção de Enguita (1997), quando informa que qualidade

Hoje em dia se identifica antes com os resultados obtidos pelos escolares, qualquer que seja a forma de medi-los [...]. Cada nova versão da qualidade não substitui inteiramente e de uma vez por todas as anteriores: a nova versão afasta as antigas para o lado, mas tem de conviver com elas. (p. 98-99)

1. 0 acesso a esses documentos foi autorizado e viabilizado pelo INEP, por meio da liberação de senha que permitiu a entrada aos sistemas de dados informatizados do MEC, particularmente o Sistema de Acompanhamento de Processos das Instituições de Ensino Superior - SAPIEnS - e Sistema de Informações da Educação Superior - SiedSup. Os demais dados trabalhados são públicos, estando disponíveis no site do INEP. 
Dessa forma, não há uma única qualidade, mas sim um consenso que é construído na medida em que a política educacional formulada conjuga os interesses de setores e grupos acerca dos aspectos a serem alcançados. Observa-se, na Educação Superior, a convivência de concepções de qualidade retratando os interesses distintos, conformando a diversificação e diferenciação de instituições de Ensino Superior.

Analisando a história da avaliação da Educação Superior brasileira, foi possível evidenciar que a avaliação, no período de 1968 a 1994, assume um papel fundamental na busca de melhoria da qualidade dos cursos de Ensino Superior, na medida em que passa a ser instrumento capaz de conter a expansão de cursos por meio da supervisão e do monitoramento.

No entanto, evidenciou-se uma ruptura na política de avaliação adotada para o período de 1995 a 2002 em relação à concepção de qualidade pretendida pelos períodos históricos anteriores.

$\mathrm{Na}$ gestão do regime militar e na Nova República, a política de Educação Superior implementada, embora com objetivos educacionais distintos, concebia a avaliação de cursos e de instituições como um instrumento capaz de gerar qualidade educacional na medida em que freava a expansão. No entanto, a concepção de qualidade desenhada no período de 1995 a 2002 desassociou a quantidade como condição para a qualidade, permitindo a expansão de instituições e cursos, notadamente privados, em proporções significativamente maiores do que a realizada nos períodos anteriores. Diante dessa lógica, a avaliação ganha novos contornos, tornando-se mais complexa, uma vez que propicia a classificação das instituições e dos cursos em vários graus (A, B, C, D e E, no caso do provão, ou CMB - Condições Muito Boas -, CB - Condições Boas -, CR - Condições Regulares - travesão e $\mathrm{Cl}$ - Condições Insuficientes -, nas avaliações de reconhecimento de cursos) e categorias distintas, proporcionadas por critérios específicos de acordo com a organização administrativa própria à instituição, como instituto superior de educação, faculdade, universidade, centro universitário, entre outras.
Dessa forma, a expansão e a diversificação institucional passam a ser regidas pela avaliação, num movimento contrário à busca de retenção que ocorreu nos períodos anteriores.

A complexidade agregada à avaliação no Ensino Superior também pode ser observada pela engenharia de sua construção, que se constitui em uma sistemática que envolveu vários instrumentos dentro de um único conjunto, inclusive imbricados com o processo de regulação. Nos períodos anteriores, que abarcam os anos de 1968 a 1994, a avaliação era composta por apenas um instrumento, a partir da avaliação, para fins de autorização e credenciamento de instituições, realizada por comissões de especialistas. A partir de 1995, efetivam-se as informações estatísticas como parte do sistema de avaliação; adota-se o provão para avaliação do rendimento dos alunos; mantém-se a avaliação de credenciamento de instituição; ainda sistematiza-se em períodos quinquenais a avaliação de cursos, criando, além da autorização e do reconhecimento de cursos, a renovação de reconhecimento de cursos e o recredenciamento de instituições.

No entanto, esses instrumentos não se articularam entre si como, por exemplo, os dados estatísticos coletados, tabulados e expressos nos Censos Educacionais não foram analisados, cotejados e/ou comparados com os demais resultados. Essa desarticulação fragilizou a adoção da única medida prevista de interferência estatal: o fechamento dos cursos que não atendessem aos padrões de qualidade estabelecidos e a suspensão temporária de prerrogativas da autonomia ou o descredenciamento de instituições, conforme disposto no art. 46 de LDB (Brasil, 1997).

Pode-se explicar essa desarticulação pelas contradições existentes no interior dos órgãos de Estado, como o Ministério da Educação - MEC - e os órgãos do poder judiciário, e também presentes no contexto das agências reguladoras e executoras do processo de avaliação como o Instituto Nacional de Estudos e Pesquisas Educacionais Anísio Teixeira - INEP -; Secretaria de Ensino Superior - SESu -; e o Conselho Nacional de Educação - CNE. 
Estes representam a fragmentação da avaliação, a partir de ações pulverizadas diante desse processo, uma vez que coube ao INEP a organização e execução da avaliação; à SESu, a preparação e instrução dos processos e notificação dos resultados das instituições; ao CNE foi incumbida a tarefa de deliberar sobre os processos; e a homologação dos atos seria formalizada pelo MEC (procedimentos definidos pelo Decreto n. 3860/2001).

Dessa forma, as ações indutoras de qualidade ficaram restritas ao ato "avaliar", concebido como monitoramento, ou melhor, como verificação, uma vez que desassociou o diagnóstico produzido pela verificação in loco e pelos resultados obtidos pelo provão do planejamento de propostas de melhoria, deixando às instituições a tarefa de saneamento dos problemas detectados.

Essa construção da sistemática de avaliação parte de uma concepção local e própria, com interferência significativa de teóricos e estudiosos que participaram como gestores dos órgãos responsáveis pela formulação e implementação da política de avaliação, evidenciada a partir da análise do material elaborado pela equipe de pesquisadores do Núcleo de Pesquisas sobre Ensino Superior da Universidade de São Paulo - NUPES - USP -, por documentos publicados pelo INEP e por pareceres do CNE. Nesse sentido, a sistemática de avaliação adotada se caracteriza como uma construção própria brasileira que, embora tenha recebido influência de organismos externos, acaba agregando contornos específicos ao longo do processo de sua configuração até chegar ao padrão de avaliação de rendimento do aluno.

Apesar da crítica sobre o processo de sua implementação, a avaliação centrada no rendimento do aluno tornou-se hegemônica, a partir da adoção de estratégias que envolviam a comunidade acadêmica. Os professores das instituições públicas, em sua grande maioria, passaram a compor as comissões de avaliação, inclusive aquelas de áreas para a realização do provão. Também se buscou apoio da sociedade civil, adotando, inclusive, mecanismos de divulgação dos resultados das avaliações por meio da chamada "prestação de contas" à sociedade, referente à qualidade do ensino que vem sendo ofertado no Brasil.

A participação ativa da comunidade acadêmica, quer na formulação da política, quer no processo de sua implementação, serviu como uma ação estratégica, que influenciou a disseminação da avaliação nos moldes desenhados, agregando conhecimentos e práticas que contribuíram na credibilidade da sistemática na sociedade e nas próprias instituições de Ensino Superior. Para tanto, elegeram-se critérios específicos de escolhas dos membros das comissões de avaliação a partir de perfis acadêmicos, o que influenciou o processo de construção da hegemonia buscada ao processo.

No entanto, não se pode deixar de mencionar a busca de apoio de diversos atores sociais, inclusive representantes de interesses corporativos como a presença dos Conselhos de Classe, dos representantes acadêmicos, das associações das instituições de ensino, além dos próprios gestores governamentais que, em certa medida, agregaram ao processo suas percepções e seus interesses. A título de exemplo, pode-se mencionar o papel da Ordem dos Advogados do Brasil - OAB - no desenvolvimento de processos próprios de avaliação de cursos que, além do Exame de Ordem ${ }^{2}$, institucionalizou o programa OAB Recomenda, que "lista os melhores cursos jurídicos do país, segundo a performance de seus alunos nas avaliações do Exame Nacional de Cursos, o Provão, e do Exame de Ordem" (OAB, 2007). Essas ações influenciam o desenvolvimento das políticas e ações do Estado na medida em que referenda os resultados do provão e da sistemática de avaliação que se tem em curso.

Nesse sentido, pode-se observar que,

[...] as relações Estado-sociedade são complexas, diversas e mediadas por uma série de questões relacionadas a cada política e

2. Os conselhos de classe dos cursos das áreas de direito, medicina, odontologia e psicologia ainda participam de forma paralela do processo de avaliação do MEC, conforme disposto no Decreto n. 3860/2001 (Brasil, 1997). 
grupo social diferenciado. 0 resultado das políticas é necessariamente contingente, sendo o papel dos atores fundamental. (Marques, 1997, p. 83)

A partir da lógica de implementação da política de avaliação, verificou-se o delineamento de uma nova concepção de qualidade que vai sendo incorporada pelas instituições de Ensino Superior a partir dos resultados do provão, somados à visão dos avaliadores constantes nos pareceres elaborados no momento das visitas in loco. Embora a política formulada procurasse romper com a concepção de qualidade presente nos períodos históricos anteriores, os avaliadores enfatizaram em seus pareceres o princípio da indissociabilidade entre ensino, pesquisa e extensão, o que induziu as instituições a forjar a presença desse princípio nos documentos exigidos pelo MEC para o processo de avaliação, mesmo no contexto das faculdades, sem, contudo, alterar os procedimentos e as ações internas, permitida em virtude da adoção de critérios de qualidade distintos de acordo com a organização administrativa das instituições.

Verificou-se um comprometimento das instituições em acatar os padrões de qualidade ${ }^{3}$ estabelecidos pelo MEC, evidenciado tanto pela análise das tendências apontadas nas estatísticas oficiais, como também presente nos pareceres das comissões de avaliação. Esse comprometimento implicou alterações na gestão institucional interna, na medida em que as escolhas para os coordenadores de cursos e de professores passaram a ter como referência os padrões de qualidade utilizados nas avaliações oficiais, assim como as decisões acerca da melhoria nas instalações físicas e acadêmicas e na forma de organização e implementação das questões pedagógicas.

No entanto, o movimento das instituições em buscar atender aos critérios estabelecidos para cada indicador de qualidade apontado pelo órgão oficial não conseguiu promover alterações nos resultados de rendimento dos alunos. Dessa forma, pode-se observar que as estratégias de se melhorar a qualidade do Ensino Superior a partir da sistemática de avaliação desenhada não foi capaz de produzir os efeitos esperados.

A análise documental desenvolvida permite inferir que não há correspondência entre os resultados do provão e os resultados das avaliações para fins de reconhecimento de curso obtidos nas instituições de Ensino Superior, uma vez que se verificou um percentual de distorção de 62,34\% entre os 77 casos analisados, enquanto que o percentual de correspondência foi de 37,66\%.

Entre os indicadores que causaram impactos positivos no contexto das diversas instituições do Ensino Superior, podem ser mencionados: a titulação dos professores, inclusive com a presença maior de professores doutores, considerando o número de alunos matriculados; a ampliação do número de professores contratados pelo regime de tempo integral; o cumprimento, na construção curricular, das diretrizes curriculares nacionais; a informatização dos serviços; a melhoria do acervo bibliográfico; a existência de laboratórios específicos; a presença de laboratórios de informática com bons equipamentos; a adequação das instalações aos portadores de necessidades especiais; entre outros. Entretanto, há alguns pontos que merecem ser destacados:

a) Se no contexto das instituições privadas foi possível detectar movimento de adesão aos indicadores, como impacto da sistemática de avaliação, houve um movimento diferenciado no contexto das instituições públicas, uma vez que estas obtiveram conceitos inferiores às instituições privadas, nas avaliações in loco, no que se refere ao corpo docente e às instalações.

No entanto, cumpre ressaltar que nos resultados obtidos pelo "provão”, as universida-

3. Os padrões de qualidade construídos pela SESu são compostos por três dimensões de avaliação: a organização didático-pedagógica; o corpo docente; e as instalações das instituições de Ensino Superior. 
des públicas obtiveram melhores resultados, sendo um percentual de $89,11 \%$ de conceitos positivos (A, B e C) e 10,89\% de conceitos negativos (D e E), enquanto que as universidades privadas obtiveram $74,16 \%$ de conceitos positivos e $25,84 \%$ de conceitos negativos. Essa relação ainda é mais visível quando se tomam os resultados das instituições não universitárias privadas, que ficaram com $29,06 \%$ de conceitos positivos e 70,94\% de conceitos negativos.

Os aspectos apontados nos pareceres das comissões de avaliação detectaram fragilidades no contexto das instituições públicas como a existência de instituição de Ensino Superior pública funcionando em prédio de instituição de educação básica; instituições com acervo bibliográfico pobre; ausência de serviços informatizados; corpo docente constituído em sua maioria por professores contratados (substitutos); carência de laboratórios de informática; prédios públicos não adequados para o acesso aos portadores de necessidades especiais.

Pode-se observar que a avaliação processada, nesse período, causou impacto distinto em relação às instituições públicas e privadas, uma vez que o formato de "controle remoto" adotado pela política do período determinou às próprias instituições a iniciativa de melhoria da sua qualidade frente aos resultados obtidos, mesmo a despeito do que previa a norma le$\mathrm{gal}^{4}$. Com isso, as instituições privadas tiveram condições de envidar esforços no sentido de se adequar aos padrões de qualidade estabelecidos pelos documentos oficiais. Em todos os formulários utilizados para os processos de avaliação para fins de autorização e de reconhecimento de cursos, estavam divulgados os critérios e a pontuação da avaliação. Com isso, as instituições privadas puderam conhecer e apontar previamente as ações a serem desencadeadas para alcançar os resultados pretendidos, enquanto que as instituições públicas estavam limitadas em suas tomadas de decisões, condicionadas a um período de crise de seu sistema de financiamento (Amaral, 2003) e às mudanças no sistema previdenciário que gerou aposentadorias precoces no contexto das instituições públicas, inclusive, as de ensino (Azevedo; Andrade, 1997; Melo, 1997). Essa situação das instituições públicas foi explicitada nos pareceres das comissões de avaliação.

b) Apesar das ações desencadeadas no cenário das instituições privadas, foi possível evidenciar que elas não foram capazes de processar alterações no rendimento dos alunos, visualizadas nos resultados do provão que, de forma geral, ficaram aquém dos resultados obtidos pelas instituições públicas. As instituições públicas, apesar dos conceitos mais baixos constantes nos pareceres das comissões de avaliação, permaneceram com os melhores conceitos obtidos pelos alunos no provão.

Essas considerações permitem inferir que há outros indicadores além dos apontados pelas três dimensões da avaliação que agregam impacto no rendimento dos alunos, inclusive considerando os aspectos socioeconômicos (Setton, 2005).

\section{Os impactos da sistemática de avaliação na qualidade das instituições de Ensino Superior}

Considerando os pareceres dos membros das comissões de avaliação, foi possível apreender a importância dada por esses atores ao desenvolvimento de atividades acadêmicas, presentes em todas as dimensões da avaliação. Esses pareceres, apesar de apontar os conceitos positivos obtidos pelas instituições privadas, sinalizaram a necessidade do desenvolvimento de pesquisa e extensão por parte do corpo docente, o que deveria ser visualizado em termos de apresentação de trabalhos em congressos e eventos científicos, bem como na publicação de artigos. Os avaliadores do MEC alertaram que,

4. A LDB traz a seguinte inscrição no art. $46[\ldots] \S 2^{0}$ : "No caso de instituição pública, o Poder Executivo responsável por sua manutenção acompanhará o processo de saneamento e fornecerá recursos adicionais, se necessários, para a superação das deficiências". 
embora haja um aumento significativo no número de mestres e doutores em regime de tempo integral nas instituições privadas, isso não se evidencia como fato efetivado por conta da baixa produção científica. As atividades acadêmicas também foram mencionadas nos pareceres ao tratar da organização didático-pedagógica do curso, na medida em que explicitaram a necessidade de envolver o corpo discente em atividades como iniciação científica, monitoria, cursos de nivelamento, projetos de extensão, visitas técnicas, entre outras atividades, ainda não presentes no contexto geral das instituições privadas. A falta de desenvolvimento de atividades de pesquisa e extensão também foi apontada pelos avaliadores ao justificar os conceitos determinados para a dimensão das instalações físicas, uma vez que sinalizaram para a ausência de salas, equipamentos e espaços destinados aos professores em tempo integral.

A partir de uma análise geral dos pareceres, foi possível observar concepções distintas entre avaliadores e avaliados, bem como entre avaliadores e gestores educacionais. Para os avaliadores, a qualidade acontece por meio da indissociabilidade entre ensino, pesquisa e extensão, dentro de uma concepção única de qualidade, independentemente da forma de organização acadêmica da instituição. Embora os avaliadores acatem os critérios presentes nos formulários de avaliação geradores dos conceitos, muitas vezes positivos, não deixam de explicitar nos seus pareceres a necessidade que veem do desenvolvimento da pesquisa e da extensão como componentes da qualidade por eles concebida. Por outro lado, para os gestores educacionais, há diferentes concepções de qualidade, na medida em que se firmam critérios diferentes para a avaliação das distintas categorias de organização acadêmica das instituições. Esses critérios se explicitam nas normas e nos documentos oficiais, o que por sua vez estão acessíveis às instituições de ensino, criando um cenário de instabilidade nas instituições ao implementar a qualidade pretendida. Diante dessas formas distintas de conceber qualidade, as instituições, particularmente as privadas, optam por atender aos princípios constantes nas normas, até porque estas acatam aos seus interesses mais imediatos, ao mesmo tempo em que procuram dar algum significado para os pareceres obtidos, fabricando uma concepção de qualidade formal e outra real.

Não se pode negar que a avaliação trouxe impacto ao contexto das instituições de Ensino Superior, o que pode ser evidenciado tanto nas análises estatísticas como nos pareceres das comissões de avaliação. Esse impacto pode ser observado, inclusive, pela força de sua função supervisora e reguladora, na medida em que induz as instituições a acatar um dado padrão de qualidade para obter conceitos positivos e se manter competindo no mercado, evidenciado a partir do processo de expansão de instituições.

Partindo da lógica da sistemática de avaliação desenvolvida no período de análise e das incongruências observadas nos resultados dos instrumentos, sobretudo explicitadas nos conceitos distintos entre instituições privadas e públicas, é possível inferir que o desenvolvimento de atividades acadêmicas pode ser apontado como indicador de qualidade que deveria ocupar um aspecto mais central dentro dos critérios usados pelos instrumentos de avaliação oficiais, buscando construir uma concepção de qualidade integradora das existentes. Acredita-se que dentro da lógica estabelecida que considera a qualidade da Educação Superior a partir do rendimento de seus alunos -, a definição e a sistematização de indicadores e critérios que levassem em consideração maiores pesos a itens como iniciação científica, monitoria, cursos de nivelamento, desenvolvimento de projetos de pesquisa e extensão, envolvendo alunos e professores e aumento da produção científica, poderiam agregar maior valor ao rendimento dos alunos, podendo incidir em alteração nos conceitos obtidos pelos alunos no provão ou mesmo outra forma de avaliação de rendimento.

Pode-se verificar que, no atual instrumento de avaliação de desempenho dos estudantes, o Exame Nacional de Desempenho do Estudante - ENADE -, os resultados dos alu- 
nos das instituições públicas, sobretudo das universidades, continuam sendo superiores aos resultados dos alunos das instituições privadas. O Resumo Técnico do ENADE 2004 traz a seguinte conclusão:

5. É bom o desempenho das IES públicas. A distribuição dos conceitos por categoria administrativa mostra que as IES públicas não só têm os maiores percentuais de conceitos altos ( 4 e 5), como têm percentuais muito superiores aos das IES privadas. Nas IES estaduais e federais os percentuais de conceitos altos chegam a cerca de $78,0 \%$, enquanto nas privadas este percentual fica em torno de 38,0\%.

6. É melhor o desempenho relativo das universidades em relação às demais formas de organização acadêmica. Além de terem um baixo percentual de conceitos baixos (1 e 2), as universidades têm 13,5\% de seus conceitos no nível mais alto (5), contra 7,9\% das Faculdades, Escolas e Institutos, 3,5\% das Faculdades Integradas e 1,8\% dos Centos Universitários. (INEP, 2005, p. 50)

Na pesquisa, pela análise das estatísticas oficiais acerca do Ensino Superior, detectou-se uma relação assimétrica na razão cursos/vagas, considerando instituições públicas e privadas. Nas instituições privadas, essa relação atinge, em média, índices cinco vezes maiores do que essa relação nas instituições públicas. Portanto, outro ponto que merece maior atenção dos gestores das políticas de avaliação refere-se ao número maior de alunos por curso nas instituições privadas, que pode ser um fator do baixo rendimento dos alunos pontuados pelo provão.

Em outras palavras, essa constatação indica a necessidade de se observar as condições em que ocorreu a expansão de vagas, pois se essa ampliação representou aumento do número de alunos por sala de aula, pode significar que aí incide um dos aspectos diferenciais, para além das questões socioeconômicas, que podem vir a influenciar na diferença no resultado do rendimento dos alunos obtidos no provão das instituições privadas em relação aos resultados mais positivos obtidos pelo alunos das instituições públicas. Dessa forma, uma maior quantidade de alunos por turma pode ser indicador a influenciar no rendimento dos alunos. Esse indicador deixou de estar presente nos instrumentos de avaliação para fins de autorização e de reconhecimento de cursos desde 2001, desconsiderando os dados revelados pelas estatísticas oficiais, o que sinaliza para uma dissociação e desarticulação dos resultados dos instrumentos que compõem a sistemática de avaliação adotada, conforme já mencionado.

As causas das incongruências, encontradas entre os instrumentos de avaliação adotados no período em estudo, incidem em diversas variáveis além das detectadas, o que implicou, na política em curso, processar modificações, na forma de avaliação, particularmente na avaliação do rendimento dos alunos, como a adoção do ENADE em substituição ao provão, que passa a ter aplicação de provas aos alunos ingressantes e também aos alunos egressos, com a possibilidade de se detectar o valor que o curso ou a instituição vêm agregando ao aluno. Ainda vem se buscando processar uma avaliação do próprio processo de avaliação (meta-avaliação), e instituiu-se a autoavaliação institucional. Os instrumentos para a avaliação de autorização e reconhecimento de cursos e de credenciamento institucional foram reelaborados.

Essas modificações vêm apontando para uma nova concepção de qualidade presente nas políticas educacionais, que era concebida como o resultado do rendimento dos alunos e agora se sinaliza, pelo Sistema Nacional de Avaliação da Educação Superior - SINAES -, para uma concepção de qualidade que intenta aferir o valor que a instituição ou o curso agregaram ao aluno. Diante dessas modificações, parece importante estabelecer articulação entre os resultados do ENADE e do Exame Nacional do Ensino Médio - ENEM -, pois se acredita que assim se abriria um espaço para análise dos impactos da 
Educação Básica no perfil de chegada do aluno ao Ensino Superior, permitindo acompanhamento e o levantamento de novas questões acerca da avaliação do conhecimento agregado e o perfil socioeconômico dos alunos.

\section{Considerações finais}

A literatura mais recente aponta para a manutenção da avaliação como aspecto central na política educacional, particularmente na produção da melhoria da qualidade do ensino, na medida em que detecta aspectos que vêm gerando alterações significativas no contexto das instituições (Franco, 2004; Pacheco; Ristoff, 2005). Cury (2003) chega a afirmar que:

A avaliação terá cada vez mais um impacto sobre a organização da educação nacional. Ela será como que um termômetro para possibilitar a qualidade necessária para que esta organização, seja no setor público, seja no setor privado, alcance os objetivos maiores da Educação Superior. (p. 486)

Dessa forma, a avaliação deve se tornar foco de estudos e pesquisas acadêmicas que visem à retroalimentação das políticas educacionais, a partir da promoção da avaliação e da meta-avaliação proposta nas políticas educacionais vigentes.

Quando se pergunta que qualidade é essa que vem sendo produzida, a resposta que as instituições vêm dando explicita uma ruptura entre a qualidade desejada e a concretizada, sinalizando para uma fragilização do poder indutor da avaliação nos moldes pretendidos. A concepção de qualidade presente nas instituições parte da busca e da apropriação das notas ou dos conceitos como significantes da sua qualidade. Diante desse quadro, forjam-se conceitos a partir de situações incipientes e momentâneas de qualidade.

As evidências constatadas a partir dos pareceres dos avaliadores - o acervo da biblioteca e os equipamentos de informática são adquiridos nos momentos anteriores à visita de avaliação; os professores em regime de tempo integral possuem quase toda a totalidade da carga horária com o ensino, em sala de aula, o que os tornam horistas com grande carga horária; a infraestrutura física existente não é compatível com o desenvolvimento de pesquisa e de extensão, uma vez que não há salas individualizadas para os professores pesquisadores; o número de laboratórios é fortemente compartilhado entre os cursos da instituição; o corpo docente não possui produção acadêmica; o número de funcionários técnico-administrativos não acompanha o crescimento do número crescente de cursos e vagas; há o aumento do número de vagas dentro de um mesmo curso sem alterar as condições de funcionamento; entre outros fatores - permite afirmar que as instituições de Ensino Superior buscam produzir seus resultados na obtenção dos conceitos positivos sem, contudo, alterar a sua lógica intrínseca, ainda arraigada na concepção de uma qualidade mínima definida nos formulários de avaliação a partir de critérios e indicadores preestabelecidos de acordo com os seus interesses, incluídos na diversificação institucional, que se constitui a partir da lógica da competição.

A busca das instituições pela obtenção de conceitos positivos nas avaliações que atestem a boa qualidade de seus serviços vem proporcionando uma qualidade formal em detrimento de uma real, o que amplia ainda mais as diversas concepções de qualidade que vem sendo construídas a partir da política que busca garantir qualidade com quantidade.

Com isso, é possível concluir que a avaliação, embora tenha gerado impactos positivos nas instituições de Ensino Superior, não vem conseguindo produzir o salto de qualidade esperado, o que sinaliza para uma tendência de perda do seu poder indutor na melhoria da qualidade do ensino nos moldes em que vem sendo desenvolvida.

Nesse sentido, volta-se à antiga questão de se repensar a avaliação não como um processo de verificação, mas como um processo de interferência e busca de qualidade, sem desassociar avaliador de avaliado. 0 desafio em garantir acesso com qualidade ainda não foi atingido. 


\section{Referências bibliográficas}

AFONSO, A. J. Avaliação educacional: regulação e emancipação. 2. ed. São Paulo: Cortez, 2000.

AMARAL, N. C. A gestão das instituições de ensino superior: o foco do financiamento. In: DOURADO, L. F.; CATANI, A. M.; OLIVEIRA, J. F. de (Orgs.). Políticas e gestão da Educação Superior: transformações recentes e debates atuais. São Paulo: Xamã, 2003. p. 219-239.

AZEVEDO, S. de; ANDRADE, L. A. G. de. A reforma do Estado e a questão federalista: reflexões sobre a proposta Bresser Pereira. In: DINIZ, E.; AZEVEDO, S. de (Orgs.). Reforma do Estado e democracia no Brasil. Brasilia: Editora Universidade de Brasília, 1997. p. 55-80.

BRASIL. Lei n. 9.394, de 20 de dezembro de 1996. Estabelece as Diretrizes e Bases da Educação Nacional. Brasília: Centro de Documentação e Informação da Câmara dos Deputados, 1997.

BRASIL. Ministério da Educação e Cultura. Decreto n. 3.860, de 9 de julho de 2001. Dispõe sobre a organização do ensino superior, a avaliação de cursos e instituições, e dá outras providências. Disponível em: <http://www.mec.gov.br/sesu/ftp/decreto/ decN3860.doc>. Acesso em: 05 jul. 2003.

CUNHA, L. A. 0 ensino superior no octênio FHC. Educação \& Sociedade, Campinas, v. 24, n. 82, p. 37-61, abr. 2003.

. Desenvolvimento desigual e combinado no ensino superior: Estado e mercado. Educação \& Sociedade, Campinas, v. 25, n. 88, p. 795-817, out. 2004.

CURY, C. R. J. Educação Superior: setor público e iniciativa privada. In: MORHY, L. (Org.). Universidade em questão. Brasília: Editora Universidade de Brasília, 2003, p. 473-486.

DIAS SOBRINHO, J. Avaliação: políticas educacionais e reformas da Educação Superior. São Paulo: Cortez, 2003.

DIKER, G. La evaluacion de la calidad como dispositivo de regulacion social. In: REUNIÃO ANUAL DA ANPED, 19., 1996, Caxambu. Anais... Caxambu, 1996. Mimeografado.

DOURADO, L. F.; OLIVEIRA, J. F. de; CATANI, A. M. Transformações recentes e debates atuais no campo da Educação Superior no Brasil. In: Políticas e gestão da Educação Superior. São Paulo: Xamã, 2003. p. 17-30.

ENGUITA, M. F. 0 discurso da qualidade e a qualidade do discurso. In: GENTILI, P.; SILVA, T. T. da (Orgs.). Neoliberalismo, qualidade total e educação: visões críticas. 5. ed. Petrópolis: Vozes, 1997. p. 93-110.

FRANCO, C. Quais as contribuições da avaliação para as políticas educacionais? In: BONAMINO, A.; BESSA, N.; FRANCO, C. (Orgs.). Avaliação da Educação Básica. Rio de Janeiro: Loyola, 2004. p. 45-63.

GOMES, A. M. Estado, mercado e Educação Superior no Brasil: um modelo analítico. Educação \& Sociedade, Campinas, v. 24, n. 84, p. 839-872, set. 2003.

INEP. Resumo técnico: Enade 2004. Brasília: INEP, 2005.

MARQUES, E. Notas críticas à literatura sobre Estado, políticas estatais e atores políticos. Revista Brasileira de Informação Bibliográfica em Ciências Sociais - BIB, Rio de Janeiro, n. 43, p. 67-102, 1º sem. 1997.

MELO, M. A. de. As reformas constitucionais e a Previdência Social (1993-1996). In: DINIZ, E.; AZEVEDO, S. de (Orgs.). Reforma do Estado e democracia no Brasil. Brasília: Editora Universidade de Brasília, 1997. p. 55-80.

NEAVE, G. On the cultivation of quality, efficiency and enterprise: in overview of recent trends in higher education in Western Europe, 1986-1988. European Journal of Education, Paris, v. 23, n. 1/2, p. 7-23, 1988.

The evaluative state reconsidered. European Journal of Education, Paris, v. 33, n. 3, 1998.

OAB. Conheça os cursos de direito recomendados pela OAB. Notícias. Brasília, 2007. Disponível em: <http://www.oab.org.br/ noticia.asp?id=1464>. Acesso em: 26 jan. 2007. 
PACHECO, E.; RISTOFF, D. Construindo o futuro. In: GENRO, T. et al. Seminário Internacional "Reforma e avaliação da Educação

Superior": tendências na Europa e na América Latina. São Paulo; Brasília: INEP, 2005. p. 45-51.

RIOS, T. A. Compreender e ensinar: por uma docência da melhor qualidade. 3. ed. São Paulo: Cortez, 2002.

RISTOFF, D. I. Avaliação da Educação Superior: flexibilização e regulação. In: DOURADO, L. F.; CATANI, A. M.; OLIVEIRA, J. F. de (Orgs.). Políticas e gestão da Educação Superior: transformações recentes e debates atuais. São Paulo: Xamã; Alternativa; NEDESC, 2003. p. 137-157.

ROTHEN, J. C. 0 vestibular do provão. Avaliação. Campinas, v. 8, n. 1, p. 27-37, mar. 2003.

SANTOS, W. dos. 0 provão: para além do discurso oficial - representação do professor e anatomia do modelo. 2001. Tese (Doutorado)- Pontifícia Universidade Católica de São Paulo, São Paulo, 2001.

SETTON, M. da G. J. Um novo capital cultural: pré-disposições e disposições à cultura informal nos segmentos com baixa escolaridade. Educação \& Sociedade. Campinas, v. 26, n. 90, p. 77-105, jan/abr. 2005.

Recebido em 02.03.09

Aprovado em 05.05.09

Giselle Cristina Martins Real, pedagoga e mestre em Educação pela UFMS, com doutorado em educação pela FEUSP, é professora adjunta da Universidade Federal da Grande Dourados 